\title{
Experiências pedagógicas de um bailarino autodidata: entrevista com Khosro Adibi
}

\author{
MARIANE ARAUJO 1 \\ PATRÍCIA CHAVARELLI²
}

\footnotetext{
Artista, graduanda em Dança pela Universidade Federal de Uberlândia, integrante do grupo de dança contemporânea Strondum, membro do Conectivo Nozes e pesquisadora/integrante no Grupo de Pesquisa Dramaturgia do Corpo-Espaço e Territorialidade.

2 Intérprete-criadora, educadora, pesquisadora. Bacharel e licenciada em dança pela Universidade Federal de Viçosa, Mestre pela Universidad Internacional Tres Fronteras/PY, docente na Universidade Federal de Uberlândia, membro do Conectivo Nozes.
} 


\section{- RESUMO}

Esta entrevista foi concedida pelo bailarino Khosro Adibi, em 23 de janeiro de 2014, a Patrícia Chavarelli e a Mariane Araújo, dentro das ações do projeto Formigueiro: Acervo e Memória, vinculado ao grupo de pesquisa Dramaturgia do corpoespaço e territorialidade. Nela, o bailarino compartilha suas experiências como pedagogo e aborda como se construiu sua formação em dança, de modo autodidata.

\section{- PALAVRAS-CHAVE}

Dança, pedagogia, autodidata

\section{- ABSTRACT}

This interview was made with the dancer Khosro Adibi, in the 23rd of january of 2014, by Patrícia Chavarelli and Mariane Araújo, as part of Formigueiro: Acervo e Memória's project actions, linked to the research group Dramaturgia do corpoespaço e territorialidade. In the interview, the dancer shares his experiences as a teacher and explains how was his self-taught formation in dance.

\section{- KEYWORDS}

Dance, pedagogy, self-taught

\section{Apresentação}

O Projeto Formigueiro, vinculado ao grupo de pesquisa Dramaturgia do corpoespaço e territorialidade, é estruturado para a construção de um acervo da memória da dança, tendo como eixo principal os artistas da dança atuantes na cidade de Uberlândia ou que participaram de ações na cidade como bailarinos, pedagogos ou coreógrafos. Ele visa gerar material de pesquisa e expandir os registros e documentações na área de dança. O projeto se articula em quatro frentes orientadas pela organização de documentos, a saber: 1) coleta de materiais a partir de solicitações de doações; 2) realização de entrevistas com artistas, buscando traçar possíveis histórias da dança, visões sobre pedagogia e criação, e filosofias de trabalho na cidade de Uberlândia, no Brasil e no exterior; 3) transcrição das entrevistas realizadas; 4) Seleção e publicação de entrevistas.

De 21 a 24 de janeiro de 2014 o grupo de pesquisa colaborou com a organização de um workshop de dança contemporânea, ministrado pelo bailarino Khsoro Adibi, e realizado na Universidade Federal de Uberlândia. Nessa ocasião, a entrevista foi realizada, focando em sua experiência didático-pedagógica e formativa.

Khosro Adibi é um artista multidisciplinar. Suas atividades incluem as artes cênicas e visuais, criação de fotos/instalações de vídeos, land art, dança experimental e performance, pesquisa em educação e também coordenação e gestão de projetos artísticos, sociais e educativos na Europa e na América Latina. Ele é graduado no curso de Fine Arts, da HKU (University of Fine Arts, em Utrecht/ NL) e estudou dança na SNDO (School for New Dance Development, em Amsterdã).

Recentemente, tem ensinado, performado e realizado exposições pela Europa e América Latina, tem regularmente treinado a companhia Rosas, em Bruxelas, o Cullberg Ballet, em Estocolmo, e a companhia Maguy Marin, em Lyon e dançou com 
o Les Ballets C. de la B.

Também trabalhou como autônomo para escolas como P.A.R.T.S (Bruxelas), Danshogckolen (Estocolmo), CODARTS (Rotterdam), Theatre School (Copenhagen). No Brasil trabalhou com companhias como Palácio das Artes, Primeiro Ato (ambas de Belo Horizonte) e Gustes Company (Araraquara) e ministrou cursos na Universidade Federal da Bahia, na Universidade Estadual de Campinas, na Universidade Federal de Uberlândia, no Centro Coreográfico do Rio de Janeiro e no Sesc Palladium, entre outros.

M: Como você começou na dança? Como foi o seu trajeto até aqui (escolas, academias ou universidades pela qual passou)?

K: Eu comecei a dança como artista visual. Eu estudei, antes da dança, artes visuais e trabalhei muito com meu corpo, por meio da fotografia, do vídeo, de instalações e performances/arte. Através disso eu tinha interesse em saber mais sobre meu corpo, de que maneira eu posso utilizar o meu corpo. Eu tive uma aula de dança uma vez, gostei muito e foi então que eu cheguei até aqui. Depois estudei na escola de Dança em Amsterdã, chamada School of New Dance Development, estudei só um ano, depois eu saí da escola. Este meu trajeto é um trajeto autodidata que atravessa minha pesquisa pessoal, com coisas que eu gostaria de observar no trabalho de outras pessoas, aprender também em aulas com pessoas que eu trabalhei.

P: Nesse ano que você fez aula, lá na escola em Amsterdã, que tipo de dança que você chegou a estudar nesse ambiente?

K: No fundo, esta escola era para "dancemakers", pessoas que criam dança. Esta escola basicamente tinha o foco na maneira como você pode construir o seu próprio caminho para criar dança. Era muito focada em composição e improvisação. Tinha aula de técnica também, mas a aula de técnica normalmente não era técnica cristalizada, como uma técnica fixa. Era mais voltada para a referência do trabalho de cada professor. Acredito que neste ano que estudei nessa escola de dança em Amsterdã, realmente eu não dancei nada. Eu tinha História do desenho, iluminação, fotografia, figurino, ou seja, temas com os quais eu já tinha contato anterior como artista visual. Todo o meu processo, no fundo, foi pensado depois dessa escola, porque quando eu parei com a escola depois de um ano, eu decidi parar com a dança. Eu fui para Nova York com a ideia de trabalhar como fotógrafo/filmador. Em Nova York pensei novamente sobre o desejo de movimentar meu corpo. E pensando outra vez melhor, eu descobri que eu não poderia deixar a dança, que eu necessitava seguir. E essa foi a direção provavelmente mais séria e independente do meu pensar com a dança. Era uma necessidade pessoal mais do que uma necessidade profissional. Foi isso.

M: E sobre a técnica que você utiliza nos workshops que ministra (Trabalho de Chão), de onde você trouxe esta referência?

K: Eu não tenho nenhuma referência específica, porque também, como disse, eu anteriormente não trabalhei com ninguém. Trabalhei com algumas pessoas que davam workshops curtos, mas eu não tenho um trajeto que desenvolveu meu trabalho com um professor. Especificamente esse trabalho iniciou quando eu tinha um estúdio em Bruxelas em 2001. Eu abri uma escola, não escola, um estúdio de dança em Bruxelas e trabalhava lá. Uma vez, uma amiga me pediu pra dar uma aula de técnica. Antes eu nunca tinha feito isso, porque meu foco sempre foi improvisação e 
contato-improvisação. E eu disse para a minha amiga "Eu não sei o que é técnica" e ela disse: "você se movimenta muito bonito, ensina para as pessoas a maneira que você se movimenta". Eu pensei em uma maneira de construir uma sequência com referência do movimento pessoal que eu tinha. Essa foi a referência que eu comecei a ter de aula técnica. E de pouco em pouco eu desenvolvi esse trabalho até onde está hoje em dia. Mas primeiro foi isso. Em segundo lugar, esse trabalho tem influência de pessoas com quem eu trabalhei, também de pessoas que eu ensinei, estudantes. Porque você faz algo, olha, observa se algo funciona ou não, identifica que algumas pessoas fazem diferente e pensa: "ok, quando ele faz diferente parece que é mais interessante do que a maneira que eu faço". Eu pego isso e desenvolvo o processo e dessa maneira eu aprendo através dos estudantes, através do processo pessoal que ensinei.

M: E foi a partir daí que você começou a dar aulas?

K: Isto. Eu nunca pensei "Preciso ter uma aula técnica" e isso, provavelmente, foi também a razão de eu nunca ter tido uma aula de técnica. Até o momento que eu cheguei a uma conclusão de que seria melhor propor uma técnica que servisse ao corpo das pessoas, que pudesse ampliar as possibilidades dentro do seu "movimento natural do corpo", do que dar uma técnica que obrigasse alguma forma ao corpo e que não tivesse realmente uma forma natural. Esta foi a minha referência. E também algo que foi muito importante, dentro da técnica para mim, foi de que a técnica precisa dar um ponto de partida. Eu disse muitas vezes: nós não dançamos com técnica, nós dançamos com o corpo. Porém entender de que maneira o corpo funciona, necessita trabalhar a mecânica do corpo basicamente, de que maneira o corpo funciona, de que maneira você pode desafiar. O que seria desafiar? Não sei, como se tivesse um desafio para levar esse movimento ou coisa para algum lugar em outro nível, vamos dizer assim. E esta foi para mim uma referência. Só que quando eu fui tentar construir um exercício, meu foco não foi realmente mostrar algo que as pessoas fazem em um espetáculo. Para mim o alfabeto é importante, de que maneira a gente entende o alfabeto do corpo e como ele pode escrever seu próprio livro, criar técnica. Esse é para mim o foco da técnica. O princípio da gravidade, de peso, de relação com o chão, a relação com o centro, de que maneira o corpo se move ao redor do centro, isso para mim é referência, não forma. Eu preciso da forma para explicar o conteúdo.

M: Então a técnica vem mais como uma ferramenta para composição do que se pensa a técnica em si, como virtuosismo?

K: Técnica necessita... Através da técnica o bailarino necessita encontrar o próprio corpo, não é mais que isso. Este é o trabalho do bailarino, como disse muitas vezes. Outra vez como um alfabeto. Tem quantas? 28 letras?

M: Por aí (risos)

K: 30. Tem trinta (risos). Pessoas escrevem livros e sempre escrevem, escrevem. Para mim é importante que as pessoas entendam o alfabeto, entendam a gramática e crie isto. Entender em seu corpo, a possibilidade do seu corpo e depois criar sua "dança", criar sua maneira de movimentar-se. Compreender o corpo não é o mesmo que compor ou criar um trabalho de dança. O trabalho do físico é pensar enquanto corpo, como um todo, um instrumento. Trabalhar composição é um trabalho externo, não interno. É um conhecimento que necessita desenvolver através da relação que você cria, para criar uma obra de dança, por exemplo, uma obra de arte. Isso corres- 
ponde a duas referências diferentes pra mim: referência externa ou referência interna. Inspiração, improvisação, técnica, são coisas que você faz enquanto corpo que pode ter uma relação com o externo, mas em primeiro lugar você precisa saber que relação você tem com o seu corpo. Como um cozinheiro, primeiro necessita desenvolver o sabor, depois pode cozinhar. O bailarino primeiro necessita "taste". Provar o seu corpo, qual sabor tem e de que maneira eu posso utilizar isso. Depois pode criar composição ou alguma obra de arte, mas primeiro precisa se relacionar com o seu corpo. Eu creio que falar de técnica é entender que ela sirva para encontrar o seu corpo. E depois que criar isso é responsabilidade de cada pessoa, um caminho individual de descobrir de que maneira chegar.

P: É como se pra você fosse muito importante compartilhar com aquele bailarino, com aquela pessoa, esses caminhos de encontro do corpo e a partir daí cada um segue o caminho que achar melhor.

K: Sim.

P: Para você, nesse momento, o que interessa é isso, esse compartilhamento?

K: Realmente eu não digo ensinar. Eu compartilho conhecimento e se você pode usar de sua maneira, muito bom. Se não pode usar, não tenho nada mais para dar. Eu quero dizer: minha perspectiva sobre educação não é ensinar, é compartilhar e provocar, para que as pessoas sigam seus caminhos. Eu não acredito que exista um método ou uma maneira certa ou errada. Isso depende da necessidade de cada pessoa, depende da sua limitação e da possibilidade do seu corpo. Esta é a maneira que eu aprendi a entender meu corpo. Creio que isso pode servir para outras pessoas. Quando eu comecei a dançar, eu tinha 33 anos. Com 33 anos as pessoas param de dançar. Quando eu foco tudo em algo que falta, eu nem mesmo começo. Mas eu tentei focar na minha qualidade pessoal e no que eu posso fazer. Foi por isso que não quis gastar energia para aprender uma técnica cristalizada. Este que é basicamente meu caminhar. E eu acredito que também esse meu caminho seja justo para qualquer pessoa, porque nós não somos o mesmo. Cada pessoa tem uma estrutura diferente de corpo e por isso possui diferentes possibilidades e limitações. De que maneira você pode tirar a qualidade de cada pessoa e de que maneira eu posso estimular isso, para desenvolver sua qualidade. Este é o meu foco basicamente. Por isso também eu não posso aceitar que você necessite fazer algo desta maneira. Não. Eu digo que meu trabalho é para criar um ambiente para os estudantes, que cada pessoa com sua limitação e possiblidade pode desenvolver seu trabalho, pode desenvolver sua criatividade. Esta é a minha referência.

M: Como você entende a improvisação?

K: Para mim, improvisação é uma filosofia de vida, não é uma técnica de dança em geral. Eu acredito que a improvisação, a respeito de dança, improvisação é... a técnica mais complicada que existe. Porque dentro da improvisação, nós temos total autonomia. Autonomia não significa que você pode fazer qualquer coisa, não. Você necessita realmente ter conhecimento sobre muito aspectos, muitos elementos da dança, da composição, dentre qualquer coisa que tenha relação com uma "obra de arte", para poder compor em tempo real. Pra mim isso também é referência. A gente usa improvisação para satisfação pessoal, improvisação para criar material para coreografia, improvisação para qualquer coisa, mas pra mim, improvisação é composição em tempo real. Isto é basicamente o que eu estou tentando internalizar/ entender na minha pesquisa pessoal. 
M: Como você pensa a composição dos seus trabalhos (o uso do espaço, a estética, etc). Como você pensa na elaboração dos seus trabalhos?

P: Hoje os seus trabalhos são todos solos?

K: É diferente. Meu trabalho tem diferentes lados. Vamos explicar o primeiro lado. Em geral na dança parece que a organizamos de tal modo como se primeiro viesse a bailarina, segundo estaria o coreógrafo e depois estaria o professor, em graus de importância. Pra mim esta hierarquia estaria inversa. Para mim o professor estaria em primeiro lugar na dança, compositor como diretor estaria em segundo e bailarino estaria por último. Eu acredito que quando estamos no palco como bailarinos, precisamos ter uma motivação muito forte e saber porque estamos ali. Pessoas com diferentes motivos estariam nesse palco. Alguns performers gostam de estar no palco, alguns são egocêntricos e outros têm algo a compartilhar com o público. Eu não consegui nenhuma razão para estar no palco, por isso coloco o bailarino no lugar mais baixo. No meio pedagógico eu sinto que tenho algo a oferecer, eu sinto que tenho algo para compartilhar, por isso esse lugar é muito importante, porque eu acredito que o sistema educativo sofre, através de algum ponto de vista que não é construtivo para os alunos. Eu acho que tenho algo para dizer. Isto é para mim o desejo por este trabalho, porque o sistema educativo, em geral, pensa de modo muito vertical. Se o professor sabe algo os alunos copiam e dessa maneira aluno bom copia o professor para segui-lo, não se pensa sobre a autonomia dos alunos. Muitas vezes não se pensa sobre criar uma identidade através do processo educativo para alunos. Eu acho que eu tenho algo forte, que através da minha experiência pessoal posso mostrar outro lado.

P: Seu interesse artístico então não é de estar em cena como bailarino ou como criador, como coreógrafo, mas como um pedagogo, um pesquisador.

K: Eu acredito que através do ensinar eu aprendo muito mais do que eu aprendi em todo o meu processo educativo. Porque, como professor, foi quando realmente um processo criativo pessoal começou a estar em um lugar em que sempre aprendo coisas. Não é aprender coisas que outras pessoas aprendem para ensinar. Isso é uma pesquisa pessoal. Eu estava em um teatro observando uma obra de arte e ela não chamou minha atenção. Através da pedagogia eu treinei minha observação para saber porque não chamou minha atenção e isto pra mim é matéria para trabalhar com algo. Para discutir de que maneira você necessita compor ou em que maneira você necessita trabalhar com o tempo, com qualquer coisa para capturar a atenção, para não perder a atenção do público. Com isso eu pude observar através das aulas, através do treinamento como professor, não como artista, que este poderia ser o meu trabalho artístico. Mas eu inverti. Muitos artistas não são bons com o corpo, mas são muito bons professores e tem ideias para trabalhos artísticos. Eu entendo assim, como no boxe: alguém estaria no ringue e alguém estaria como um pequeno treinador que diz "esquerda, direita, tá, tá, tá". Este último não poderia estar dentro do ringue, mas ele saberia de que maneira o boxeador poderia proteger o seu corpo. Esta é a minha visão: eu estaria fora, eu não estaria dentro do ringue. Eu acredito que eu tenho uma ideia sobre de que maneira eles necessitariam estar dentro.

M: E quais são os seus projetos em que você está trabalhando atualmente?

K: Eu atualmente trabalho... Para mim, trabalho tem três diferentes campos. Eu faço esse trabalho educativo que basicamente consiste em mudar para diferentes lugares dando workshops. Através dos workshops eu encontrei pessoas que eu tenho 
interesse por elas. Eu chamo essas pessoas para um laboratório que eu chamo de I.P.L., International Performance Lab. Este laboratório eu comecei a pensar em 2005, quando eu tinha uma escola de dança em Bruxelas, e encontrei muitas pessoas totalmente perdidas. Aí eu pensei de que maneira eu poderia apoiar o processo da comunidade. Juntei essas pessoas no estúdio e comecei o trabalho com elas para decidir o que fazer, ao invés de esperar alguém tocar a minha porta para que eu fizesse algo. Vamos pensar em criar nosso próprio trabalho. Este trabalho foi em outro nível: muitas vezes também eu realmente não ganho dinheiro para isto, eu coloco dinheiro para isto. Outro trabalho, outro campo deste trabalho educativo e social foi através do trabalho artístico que eu fiz com o I.P.L. pensando na América Latina. Porque eu cheguei na Argentina primeiro em 2005 com ideia de fazer esse trabalho artístico com as pessoas, mas quando eu vi a realidade de pessoas que dormiam em caixas e não tinham realmente uma estabilidade social, confrontei com o meu passado porque eu passei pela mesma realidade e na mesma sociedade. Eu também não tinha realmente uma família que tinha um poder econômico. Esse confronto comigo me fez buscar uma maneira de ver de que modo eu poderia usar meus conhecimentos e ideias para apoiar o processo criativo das pessoas na comunidade, através do trabalho educativo e social. Basicamente eu chamei artistas para trabalhar no I.P.L. em um lugar específico. Por exemplo, aqui no Brasil desenvolvi o trabalho em Matão, pequena cidade do interior em São Paulo, e chamei os artistas da comunidade, não só para ministrar workshops, mas algo mais. Alguns realmente que moravam em periferia, pessoas em formação, pessoas que realmente não tinham contato com.... eu uso a palavra processo criativo, porque arte tem uma imagem de elite, um pouco uma conotação de que arte é para artista. Mas a fundação da arte, para mim, é o processo criativo. E isso pode ocorrer na cozinha, ou na lavanderia, dentro de qualquer lugar. Eu acredito que muitas vezes quando dizemos que a comunidade é pobre, em primeiro lugar pensamos na experiência sobre as pessoas que não têm dinheiro. Mas em comunidade pobre não é por causa de dinheiro que falta educação e processo criativo na comunidade. Quando realmente o processo criativo é presente nas pessoas, as pessoas conseguem formas de melhorar a condição de vida. Por exemplo, dar dinheiro para pessoas que não sabem o que fazer com isso, depois de um mês estariam no mesmo lugar, justamente porque não sabem o que fazer com isso. Isto para mim é basicamente a parte mais importante do meu trabalho. Trabalho para unir o artístico, o social e o educativo também, em Fronteiras ${ }^{3}$, por exemplo.

M: Como você vê a dança contemporânea atualmente?

$\mathrm{K}$ : Eu acredito que basicamente, pessoas que dizem "mundo dança contemporânea", isso significa Europa e Estados Unidos e este não é o mundo. O mundo é maior que isso, mas para muitas pessoas o mundo significa isso. Infelizmente para muitas pessoas fora desse mundo também mundo significa isso. Para mim dança contemporânea é algo que passa hoje em dia aqui em Uberlândia neste estúdio,

\footnotetext{
O festival internacional de artes Fronteiras é uma plataforma multidisciplinar para a troca e desenvolvimento de arte e educação entre artistas e seus ambientes diretos. Um projeto envolvendo ampla gama de públicos e atividades: desde áreas desprivilegiadas e periféricas até reconhecidas e profissionais organizações ou institutos na cidade, juntando arte de palco, música, multimedia, artes manuais e visuais assim como literatura, ciência e cuidados com a saúde. Atividades estas oferecidas para universidades, escolas, centros culturais, organizações culturais públicas e privadas, assim como prisões, orfanatos, organizações que trabalham com psiquiatria, moradores de rua e pessoas desfavorecidas. Visa a ativação do clima cultural para estes locais específicos e gerar um processo criativo nos indivíduos.
} 
não é mais que isso. Pessoas precisam construir o seu próprio trabalho e conseguir sua própria identidade nesse espaço contemporâneo. Não tem que realmente dizer que dança contemporânea é Pina Bausch, dança contemporânea é, não. Acho que crio meu trabalho com todo respeito para muitas pessoas que realmente tem muita dificuldade para desenvolver algo muito sólido dentro da sua comunidade. Isso acontece por sua cultura, por sua maneira de observar, por sua maneira de perceber o trabalho com corpo. Esse trabalho não é o mesmo na África, não é o mesmo na América Latina, porque toda cultura tem sua própria maneira de relacionar-se com o corpo, de relacionar-se com a sua "dança". E uma razão para mim da existência do trabalho Fronteiras é exatamente isso: construir e buscar sua própria identidade dentro da cultura. Acredito que esta cultura tem o potencial para criar a sua "dança contemporânea". Esta é basicamente minha visão. Eu não sei nada sobre dança contemporânea. Porque, outra vez, eu não busco uma forma cristalizada, eu tento buscar um caminho próprio e tentar aplicar em culturas com suas necessidades próprias. Cada um pode tirar informação e formar sua "dança", a partir do que se passa nesse momento e no agora.

M: E foi por essa busca que você começou a viajar tanto, a ir a tantos países para, além do ensino da dança, buscar conhecimento, e entender como se dão esses processos?

K: Eu acredito que isso me ajudou a observar diferentes realidades, porque quando nós estamos no próprio solo, tudo que passa é isso, mas quando saímos do contexto e entramos em outro contexto é possível observar quais as riquezas dentro do próprio contexto e o que falta dentro desse contexto próprio. E esse é um processo de aprendizagem muito rico, e por isso eu não necessito do professor da Universidade. Eu aprendi através da experiência da vida, através da sua própria experiência e também aprendi a utilizar a intuição, que hoje em dia os outros deixam passar muito na sociedade moderna. Tudo necessita ter uma relação lógica, uma relação matemática, mas o lado sensível da coisa, o lado pelo qual nós nos relacionamos através do sentido, não são muitas pessoas que dão valor a isso. Quando você diz "alguém sente isso", não significa muito. Você necessita saber isso, e depois você dá valor nisso. Eu acredito que esse lado é ativado através do processo criativo, o que basicamente nós chamamos de arte. Visão, audição, coisas que você sente, isso ativa os sentidos das pessoas. Mas eu me movimento em geral pelo meu interesse. Não tenho uma casa realmente, não tenho um espaço físico. Formalmente sou holandês mas nasci no Irã. Eu trabalho na América Latina. Onde eu estaria? Não sei. Eu creio que o mundo é a minha grande cidade e as pessoas são a minha comunidade, e não é mais que isso. Falar em diferentes idiomas e em diferentes culturas, não importa para mim. Muitas pessoas me perguntam porque eu faço esse trabalho na América Latina, se não sou latino. Para mim essa é a minha comunidade. Não é Latina. É uma comunidade como a minha e me importa esta comunidade, não importa se agora é na Sibéria, na África ou América Latina. Eu sou um nômade, eu tenho orgulho em dizer isto.

M: E como você vê essa relação de ensino na Universidade, na Instituição? Como você percebe isso? Você acha que é interessante ou não? Você acha que a dança deve ser uma experiência fora de um lugar fechado, sem um sistema de notas?

K: Eu acho que a sociedade tem uma estrutura e que não dá pra romper essa 
estrutura totalmente, mas pode-se renovar isso, pode-se melhorar isto. Estrutura existe. Você não pode começar a partir do nada. Por exemplo: "vamos para campo, não sei, tirar a roupa e ver o que isso cria em nós". Não. Tudo está aí. Mas de que maneira você fortalece toda a estrutura para melhorar a condição da vida das pessoas? Na Universidade por exemplo. Universidade é um lugar muito potente, tem muita potência. É um lugar realmente muito bonito em que toda nova geração passa. Essa responsabilidade é dessas pessoas, para amanhã construir novo futuro para a nova geração. Mas algo que falta no meu ponto de vista nas Universidades é melhorar o sistema educativo que tem muitos erros. O sistema educativo, para mim, não cresce com a necessidade do tempo, com a necessidade das pessoas hoje em dia. Isso que eu acredito. Não é só na Universidade mas é o sistema educativo em geral, porque foca na massa e serve para mostrar que posição individual pode-se tomar em sociedade, mas não serve às necessidades individuais das pessoas. Muitas pessoas estão totalmente perdidas em suas vidas, não sabem o que fazer com a vida, porém funcionam muito bem em sua posição. Porque? Porque realmente no sistema educativo concentram sua atenção em que maneira podem fazer o trabalho muito bem. Agora, o que sentem, o que fazem enquanto pessoas, não é realmente importante. Ninguém dará atenção a isso. Isso cria um desequilíbrio, não há equilíbrio. Certeza que nós temos responsabilidades com a comunidade. É necessário de alguma maneira fazer um acordo nesta sociedade. Mas como uma pessoa, eu necessito ser uma pessoa saudável para esta viagem, para ensinar pessoas, ensinar melhores relações. Este lado falta totalmente, faltam seres humanos dentro da educação, na parte humana da educação, falta em geral. A parte prática desta viagem. Eu necessito de dinheiro, do administrativo, a gente necessita de médico, e isso, isso, isso..., sim, mas eu necessito de atenção de pessoas como humano, não como parte de um grande mecanismo.

M: E como você vê/entende essa relação de arte e vida?

K: Para mim não tem separação. Eu acredito que é necessário viver para aprender o que se quer fazer dentro de um trabalho criativo. Experiência e trabalho artístico não é como chegar aqui com nada. A experiência chega através da vida. Eu acredito que essa relação é necessária para saber onde está a raiz. Essa árvore está aqui porque tem uma raiz, o lugar de onde tira nutrientes e dessa maneira nós podemos crescer. Porém quando separa isso, que outra vez, digo que é resultado do sistema educativo, tudo fica desconectado, desconectam-se diferentes partes de nós: parte espiritual, parte criativa, parte funcional, parte prática, como se fossem diferentes corpos. Eu faço meu trabalho, agora vamos para casa e seguir a vida. Não, trabalho necessita que você tenha paixão. Quantas pessoas hoje em dia estão em uma posição na sociedade em que são felizes com o seu trabalho? Não muitas. Quando você realiza um trabalho com paixão, a qualidade do trabalho também é diferente. Não importa se trabalha com o serviço administrativo, limpando a casa, ou não sei, sendo cozinheiro, ou com algo em dança. É o mesmo. Porque você faz com uma motivação muito forte, não faz como uma parte fora de você, isso eu acredito mais.

P: Muito disso que você fala está presente nas suas atitudes, na sua maneira de tratar as pessoas, no respeito com que você trata cada um. Não sei se você considera interessante falar algo mais sobre isso, porque essa entrevista só se completaria mesmo com uma filmagem sua em sala, mostrando sua relação com as pessoas. Tem alguma informação sua ou sobre seu modo de pensar, sobre sua vida, que você 
acha que poderia ser importante compartilhar?

K: Eu acredito que algo muito importante pra mim é realmente estar aberto para aprender, porque isso não pára. Em uma Universidade quando você recebe o diploma, não significa que você terminou. Pensar. Para mim essa é a diferença. Eu disse, eu não tenho formação formal realmente, é... Eu tenho uma educação formal (risos). Mas a minha referência não é uma educação formal, minha referência é uma educação dentro da sociedade. Coisas que eu aprendi através de observações que passam realmente na "vida real" das pessoas, não a vida abstrata que nós criamos. Para mim, observação é uma coisa muito importante em geral. Onde eu nasci, tem uma imagem, como uma imagem de sabedoria, inteligente, uma imagem muito inteligente, que não sei se existe na história realmente ou não. Se você observar coisas que pessoas não gostam, você não faz, se você observar coisas que as pessoas apreciam, você faz. Você aprende isso. Eu sou assim para $n$ coisas. Eu observo se uma aluna faz de alguma maneira que não funciona. Ok, isso não funciona. Vamos buscar outra maneira. Em sociedade, algo que realmente ajuda alguém... não sei, eu não tenho muitas palavras... ajuda não é a palavra... mas eu não tenho outra. De que maneira conseguimos estimular coragem nas pessoas, para esse tipo de coisa. E eu tento com minha consciência pessoal medir isso, o que é certo ou não pra mim, e aplicar isso na vida. Eu acredito que é sobre isso. Estar aberto, observar, aprender coisas que passam na vida, e pra isso não precisa da universidade, está em qualquer lugar da vida. Para mim, fora é mais puro do que dentro de um sistema cristalizado, como escola. Pode aplicar em qualquer campo da vida, não sei.

P: Às vezes nós temos alunos que entram na faculdade com mais de trinta anos e acho que ficam em dúvida se devem fazer faculdade de dança por causa de sua idade para dançar e você trouxe esse testemunho de que começou a dançar com trinta e três anos. Tem alguma coisa da sua história de vida que você gostaria de compartilhar para estimular essas pessoas?

K: Como disse antes, é... nós em geral pensamos o quão vazio está isso (garrafa de água). Não vemos o quanto está cheio isso. Vamos olhar o que está cheio na vida. $\mathrm{O}$ que eu tenho e não o que falta. Esta em geral é minha observação sobre tudo. $\mathrm{E}$ também sempre achamos que temos que viver igual a outras pessoas, mas não temos. De que maneira eu posso ajudar, de que maneira eu posso contribuir com algo para o processo dessa pessoa, para esta chegar em outro nível? Você não observa o que falta em você, observa o que está em você. E isso pra mim é a filosofia de tudo, dança, qualquer coisa. E eu acredito que possa chegar em algum lugar. Pegue 20 pessoas, dê aula e queira que todas as pessoas cheguem em um mesmo nível. No fundo quando 20 pessoas chegarem no nível, não é nível mais, porque todo mundo está no mesmo lugar. Agora, se observar qual qualidade pessoal de cada um, criamse 20 diferentes níveis individuais que tenham vinte maneiras diferentes para trabaIhar e colocar atenção onde está a qualidade das pessoas, ao invés de esquecer tudo que se tem. Quando todo mundo grita, não se escuta nada mais. Eu acredito que isto é algo que falta no sistema educativo, que é padronizado. Pra mim é pensar sobre pessoas com sua própria qualidade e limitação. É isso. 